\title{
Investigation of chips morphology after turning of materials applied in aerospace industry
}

\author{
Marek Rybicki ${ }^{1, *}$, and Piotr Szablewski ${ }^{2}$ \\ ${ }^{1}$ Poznan University of Technology, Faculty of Mechanical Engineering and Management, ul. \\ Piotrowo 3, 60-965 Poznan, Poland \\ ${ }^{2}$ Pratt \& Whitney Kalisz, ul. Elektryczna 4a, 62-800 Kalisz/ PWSZ Kalisz, Poland
}

\begin{abstract}
In the paper is presented analysis of chips morphology after turning of three groups of modern materials applied in aerospace industry: titanium alloys, stainless steels and heat resistant alloys. Various feed rates $f$ and corner radiuses $r_{\varepsilon}$ as well as recommended cutting speed $v_{c}$ for given group of work material were applied in machining tests. Range of burrs on thinner edges of chips and serration on the chips surface occurrence were identified dependent on work material and uncut chip thickness (values of the $f$ and $r_{\varepsilon}$ ). In the research height $h$ and distance $b$ between the burrs as well as distance $a$ between serrated segments were measured. It was identified two kind of burrs connected with different physical phenomenon and specified $h$ and $b$ dimensions.
\end{abstract}

\section{Introduction}

During machining of materials in group $\mathrm{M}$ (stainless steels) and S (heat resistant alloys, titanium alloys) continuous chips are formed due to the materials properties. When cutting speed and federate is increased, chips types is changed to serrated or share localized type [1-4]. Connection of chips types with cutting parameters is attributed to changes of cutting temperature [1], what is confirmed by another chips types formation during hybrid, laser assisted or cryogenic machining of the materials [5-6].

The chip formation process can lead to fluctuation of cutting force, vibration and poor surface quality $[2,7]$.

On edges of chips can be visible burrs of height and frequency depending on cutting parameters. Burrs forming at thinner edge of chips (on the non-free end)can affect machined surface roughness [4]. The burrs arise due to instability of chips formation when thickness of cut is smaller than minimal.

Authors [4] have revealed that at the critical cutting speed, both pitch $b$ and height hof chip burrs reach the lowest value and serrated chips begin to appear above the speed. At the critical speed machined surface roughness had the smallest value.

\footnotetext{
${ }^{*}$ Correspondingauthor: marek.rybicki@put.poznan.pl
} 


\section{Range, conditions and technique of research}

Machining was carried out on the CTX 310 ECOLINE turning machine made of DMG. During turning flood cooling/lubrication by emulsion: CIMTECH M21-02 made of Cimcool Industrial Products B. V. with concentration 10,45 \%was used. Five work materials were machined:

- heat resistant alloy Waspaloy (EN: 2.4654; AISI: AMS 5706),

- heat resistant alloy Inconel 718 (EN: 2.4668; AISI: AMS 5662),

- heat resistant alloy Inconel X750 (EN: 2.4669; AISI: AMS 5667),

- stainless steel (EN: 1.4541; AISI: 321) and

- titanium alloy (Ti6Al-4 Grade5).

In turning tests were used Sandvik cutting inserts CNMG1204 with the SM chip breaker made of sintered carbide grade 1125. Applied holder DCLNL 2020K12 gave tool cutting edge angle $\kappa_{r}=95^{\circ}$.

Three corner radiuses $r_{\varepsilon}$ with various range of feed rates, were applied (table 1). Recommended cutting speed $v_{c}$ for given group of work material was applied in machining tests: $v_{c}=35 \mathrm{~m} / \mathrm{min}$ for heat resistant alloys, $v_{c}=150 \mathrm{~m} / \mathrm{min}$ for stainless steel and $v_{c}=75$ $\mathrm{m} / \mathrm{min}$ for titanium alloy.

Table 1. Values of feed rates $f$ applied for various corner radiuses $r_{\varepsilon}$

\begin{tabular}{|c|c|c|c|}
\hline $\begin{array}{c}\text { Corner radius } \\
\boldsymbol{r}_{\varepsilon}[\mathbf{m m}]\end{array}$ & $\mathbf{0 , 4}$ & $\mathbf{0 , 8}$ & $\mathbf{1 , 2}$ \\
\hline \multirow{4}{*}{$\begin{array}{c}\text { Feed rates } \\
f[\mathrm{~mm} / \text { rev }]\end{array}$} & 0,01 & - & - \\
\cline { 2 - 4 } & 0,02 & 0,02 & - \\
\cline { 2 - 4 } & 0,03 & 0,03 & 0,03 \\
\cline { 2 - 4 } & 0,05 & 0,05 & 0,05 \\
\cline { 2 - 4 } & 0,09 & 0,09 & 0,09 \\
\cline { 2 - 4 } & - & 0,17 & 0,17 \\
\cline { 2 - 4 } & - & - & 0,33 \\
\hline
\end{tabular}

The chips were inspected on stereoscopic microscope SteREO Discovery V20 with AxioVision software made of Zeiss. Images of chips were made with 9 and 80 magnification. In the chips were measured following dimensions (fig. 1):

- burrs height on thinner edge of chip- $h$,

- distance between burrs on thinner edge of chip - $b$,

- distance between segments on rough surface of serrated chips $-a$.

It was assumed that burrs are large when its height $h>0,1 \mathrm{~mm}$ (usually $b>0,2 \mathrm{~mm}$ ) and small when $0,02 \mathrm{~mm}<h \leq 0,1 \mathrm{~mm}$ (usually $0,05 \mathrm{~mm}<b \leq 0,2 \mathrm{~mm}$ ).

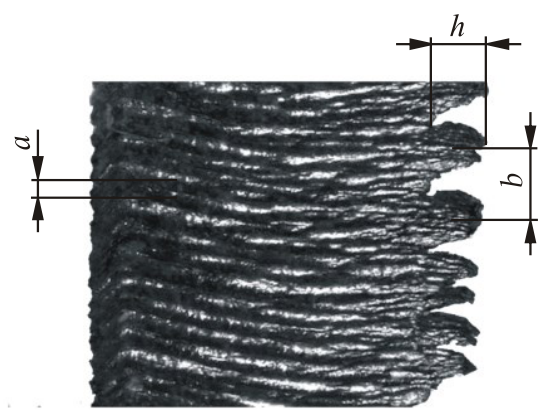

Fig. 1. Measured dimensions of chip: burrs height $h$, burrs distance $b$ and segments distance $a$ 


\section{Results and analysis of research}

From the table 2 follows that large burrs on chips edges occurs for smaller federates $f$ and higher corner radiuses $r_{\varepsilon}$ (smaller thickness of cut) most often. Smaller burrs are usually connected with serration of chips surface. The serration is visible for stainless steel and titanium alloy only, what is connected with higher cutting speed $v_{c}$ applied for the materials, the most probably [1-2].

Table 2. Occurrence of burrs on thinner edge of chip and serration of its surface for various work materials and machining conditions

\begin{tabular}{|c|c|c|c|c|c|c|c|c|c|c|}
\hline \multirow{2}{*}{ 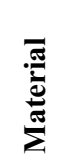 } & $\begin{array}{c}\text { Chips } \\
\text { properties }\end{array}$ & \multicolumn{3}{|c|}{ Large burrs $^{1}$} & \multicolumn{3}{|c|}{ Small burrs ${ }^{2}$} & \multicolumn{3}{|c|}{ Surface serration } \\
\hline & & 0,4 & 0,8 & 1,2 & 0,4 & 0,8 & 1,2 & 0,4 & 0,8 & 1,2 \\
\hline \multirow{7}{*}{$\begin{array}{l}\frac{\partial}{\pi} \\
\frac{\pi}{\pi} \\
\frac{0}{\pi} \\
3 \\
3\end{array}$} & 0,01 & & & & & & & & & \\
\hline & 0,02 & & $X$ & & & & & & & \\
\hline & 0,03 & & $X$ & & & & & & & \\
\hline & 0,05 & & $X$ & $\mathrm{X}$ & & & & & & \\
\hline & 0,09 & & $\mathrm{X}$ & $\mathrm{X}$ & & & & & & \\
\hline & 0,17 & & $X$ & $X$ & & & & & & \\
\hline & 0,33 & & & & & & $X$ & & & \\
\hline \multirow{7}{*}{ 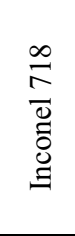 } & 0,01 & & & & & & & & & \\
\hline & 0,02 & & & & & & & & & \\
\hline & 0,03 & & $\mathrm{X}$ & & & & & & & \\
\hline & 0,05 & & $\mathrm{X}$ & & $\mathrm{X}$ & & & & & \\
\hline & 0,09 & & $\mathrm{X}$ & $\mathrm{X}$ & $\mathrm{X}$ & & & & & \\
\hline & 0,17 & & $\mathrm{X}$ & $\mathrm{X}$ & & $X$ & & & & \\
\hline & 0,33 & & & & & & & & & \\
\hline \multirow{7}{*}{ 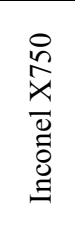 } & 0,01 & & & & & & & & & \\
\hline & 0,02 & $X$ & & & & & & & & \\
\hline & 0,03 & & $X$ & $X$ & $\mathrm{X}$ & & & & & \\
\hline & 0,05 & & $\mathrm{X}$ & $\mathrm{X}$ & $\mathrm{X}$ & & & & & \\
\hline & 0,09 & & & $\mathrm{X}$ & $X$ & & & & & \\
\hline & 0,17 & & & & & & $X$ & & & \\
\hline & 0,33 & & & & & & & & & \\
\hline \multirow{7}{*}{ 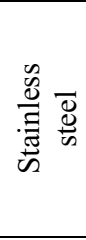 } & 0,01 & & & & & & & & & \\
\hline & 0,02 & & & & & & & & & \\
\hline & 0,03 & & $X$ & $\mathrm{X}$ & & & & $\mathrm{X}$ & & \\
\hline & 0,05 & & $X$ & $\mathrm{X}$ & & & & $\mathrm{X}$ & $X$ & \\
\hline & 0,09 & & & $X$ & $\mathrm{X}$ & $\mathrm{X}$ & & $\mathrm{X}$ & $\mathrm{X}$ & $\mathrm{X}$ \\
\hline & 0,17 & & & & & $X$ & $\mathrm{X}$ & & $X$ & $X$ \\
\hline & 0,33 & & & & & & $\mathrm{X}$ & & & $X$ \\
\hline \multirow{7}{*}{ 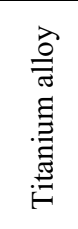 } & 0,01 & $X$ & & & & & & & & \\
\hline & 0,02 & & $\mathrm{X}$ & & $\mathrm{X}$ & & & & & \\
\hline & 0,03 & & $\mathrm{X}$ & $\mathrm{X}$ & $\mathrm{X}$ & & & & & \\
\hline & 0,05 & & $\mathrm{X}$ & & $\mathrm{X}$ & & $X$ & & & \\
\hline & 0,09 & & & & $\mathrm{X}$ & $\mathrm{X}$ & $\mathrm{X}$ & $\mathrm{X}$ & $X$ & $X$ \\
\hline & 0,17 & & & & & $\mathrm{X}$ & $\mathrm{X}$ & & $X$ & $X$ \\
\hline & 0,33 & & & & & & $X$ & & & $X$ \\
\hline
\end{tabular}

During machining of Inconel 718 with conditions: $r_{\varepsilon}=0,8 \mathrm{~mm}, f=0,17 \mathrm{~mm} / \mathrm{rev}$ was observed transient state. On chip formed in the conditions is visible all cases of chips morphology: irregular large and small burrs and beginning of the chip serration in form of surface waviness (fig. 2). 


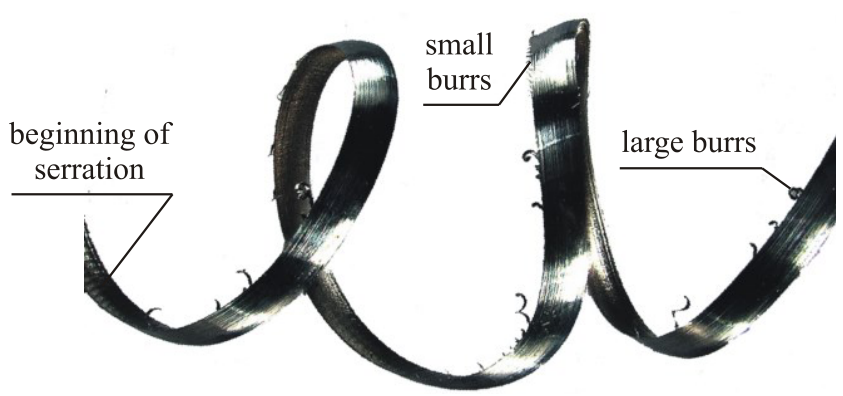

Fig. 2. Occurrence of large and small burrs as well beginning of segments formation on rougher surface of chip (Inconel 718, $r_{\varepsilon}=0,8 \mathrm{~mm}, f=0,17 \mathrm{~mm} / \mathrm{rev}$ )
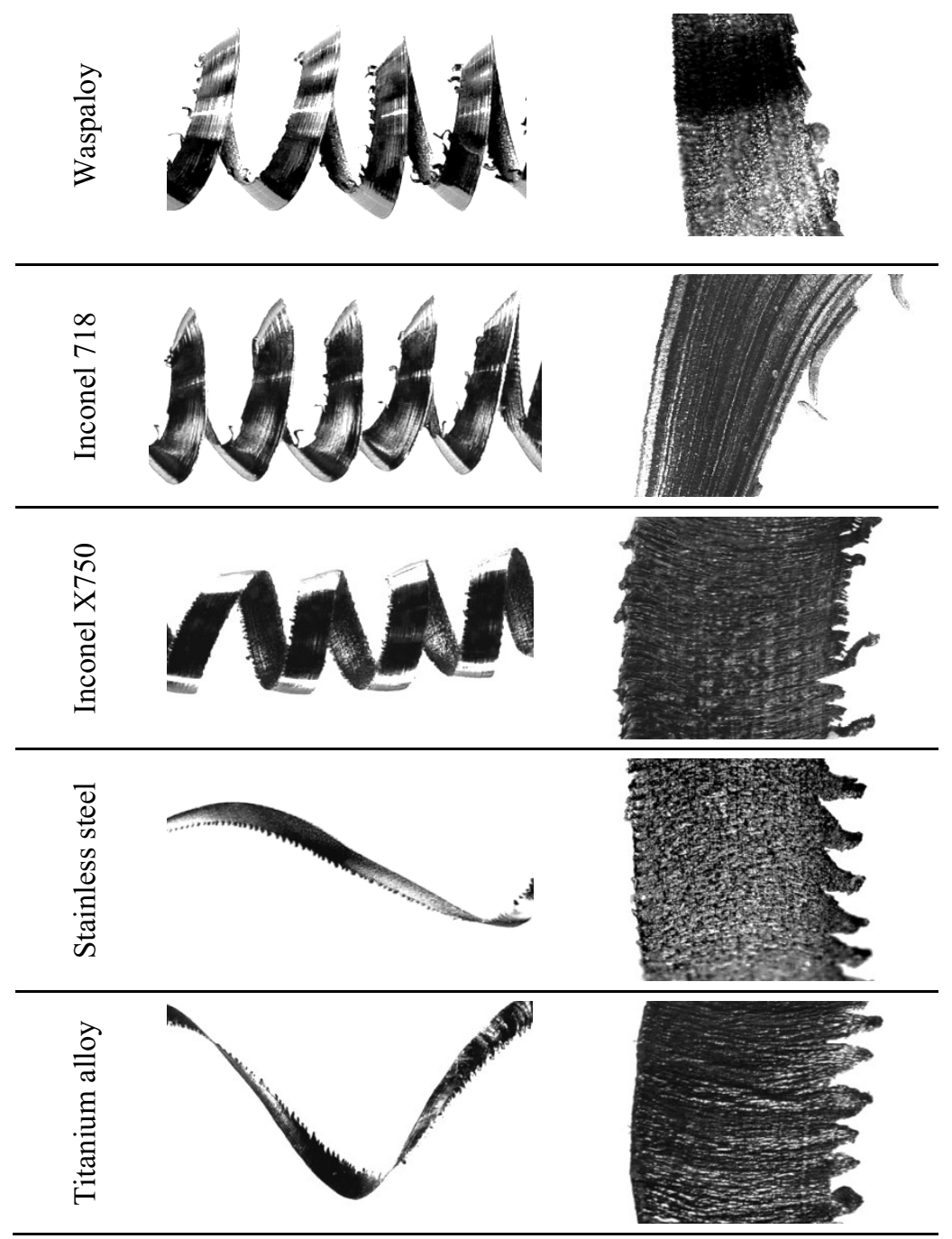

Fig. 3. Views of shape and rougher surface of chips after turning of various materials $\left(r_{\varepsilon}=0,8 \mathrm{~mm}, f=0,03 \mathrm{~mm} / \mathrm{rev}\right)$ 


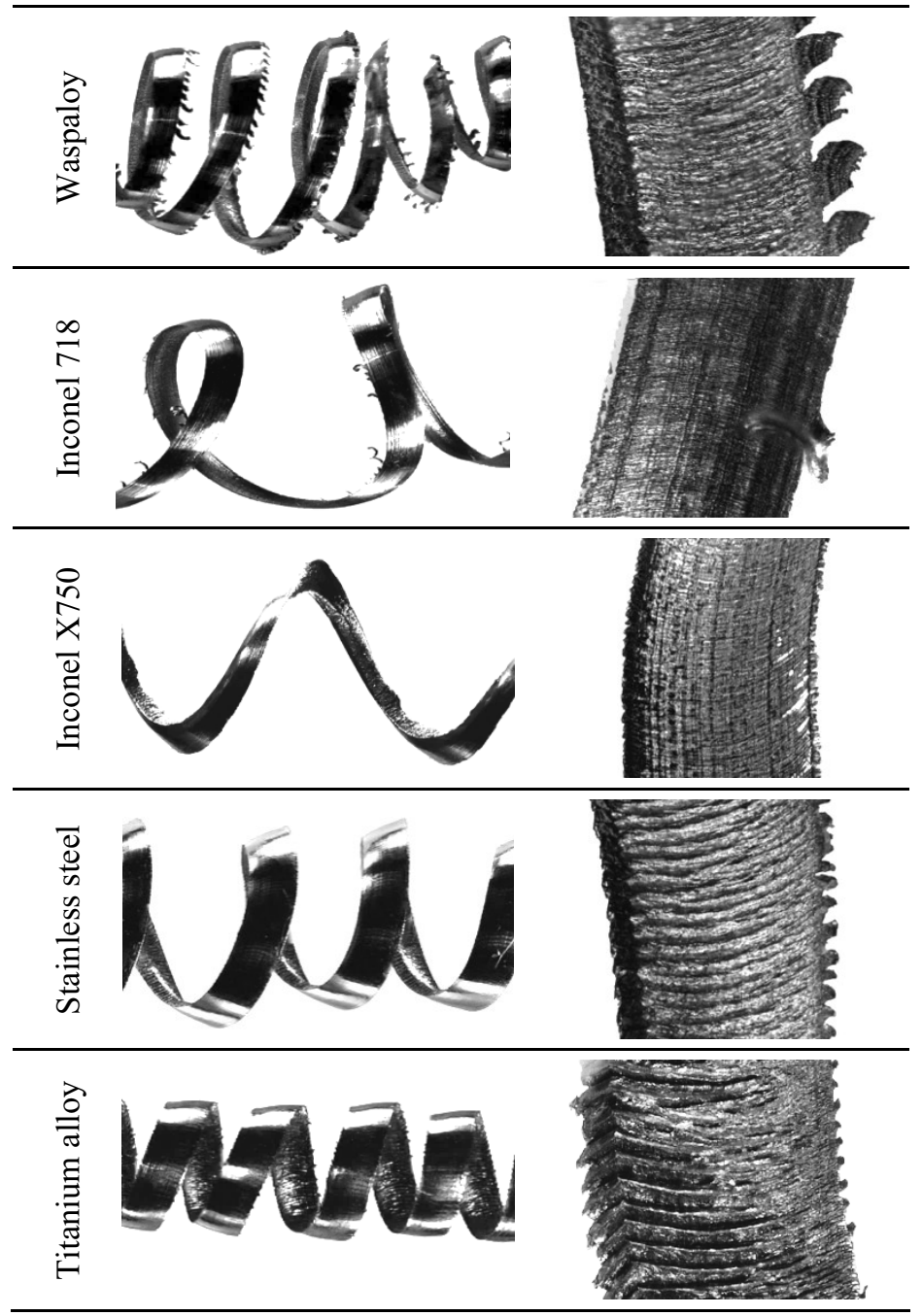

Fig. 4. Views of shape and rougher surface of chips after turning of various materials $\left(r_{\varepsilon}=0,8 \mathrm{~mm}, f=0,17 \mathrm{~mm} / \mathrm{rev}\right)$

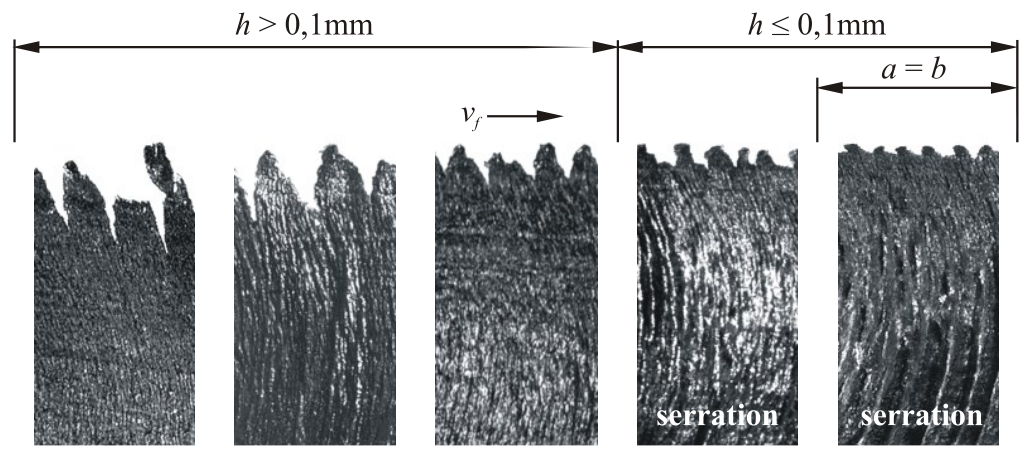

Fig. 5. Influence of federate on chips morphology during turning of titanium alloy $\left(r_{\varepsilon}=0,8 \mathrm{~mm}\right)$ 


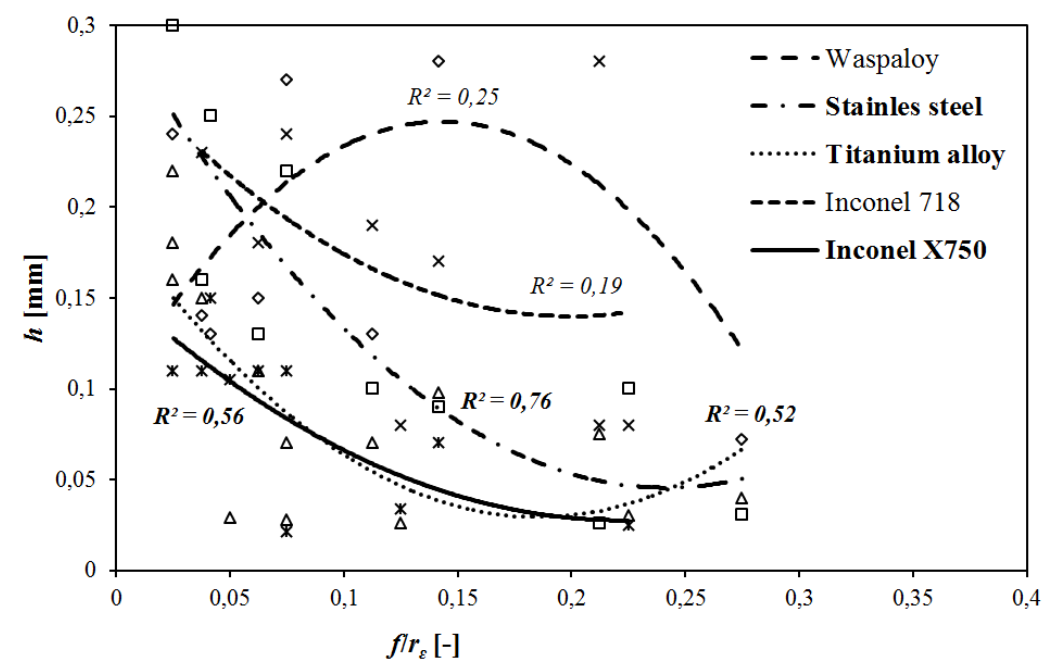

Fig. 6. Influence of ratio $f / r_{\varepsilon}$ on chips burr height $h$ after turning of various materials

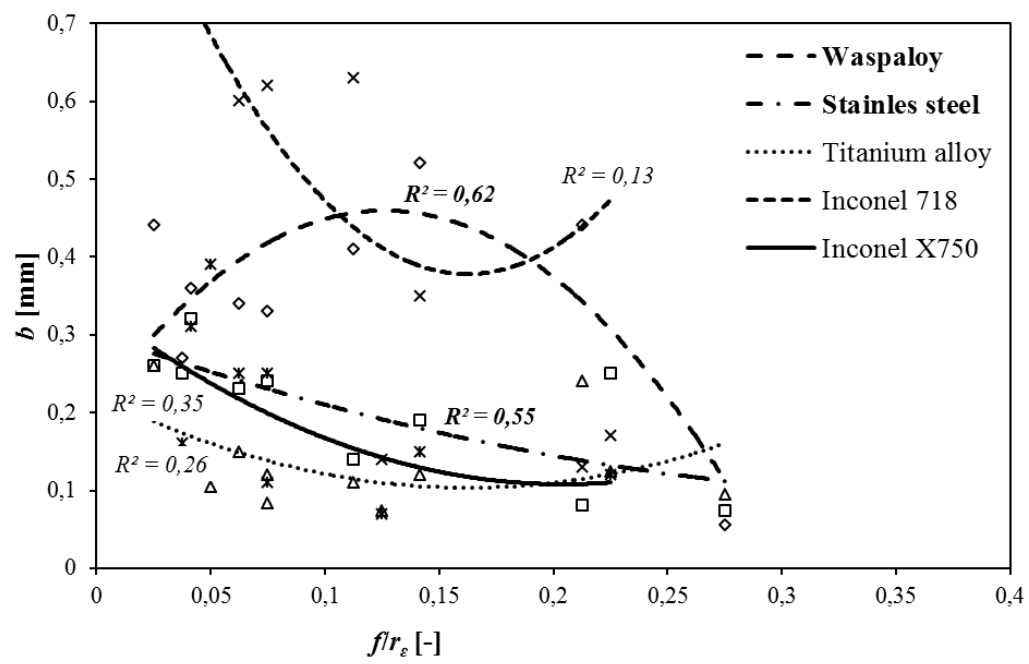

Fig. 7. Influence of ratio $f / r_{\varepsilon}$ on chips burr distance $b$ after turning of various materials

At figures 3 and 4 is presented views of chips after machining with the most popular corner radius $r_{\varepsilon}=0,8 \mathrm{~mm}$ and two federate values: $0,03 \mathrm{~mm} / \mathrm{rev}$ and $0,17 \mathrm{~mm} / \mathrm{rev}$ respectively. From the figures follows that all the chips have tubular shape, except chips after turning of stainless steel and titanium alloy with small federate.

For smaller federate regular large burrs are visible for all of the materials and for higher federate large burrs is visible for the Waspaloy alloy only. Smaller burrs distance is equal to serration distance $a=b$ usually, what is especially visible after turning of stainless steel and titanium alloy (fig. 4,5).

At figures 6 and 7 is shown influence of the $f / r_{\varepsilon}$ ratio on the chips burrs height $h$ and distance $b$. The $f / r_{\varepsilon}$ ratio is proportional to thickness of cut, affecting chip formation. Applied ratio allowed to relate the chips burrs dimensions to the specific combination of $f$ and $r_{\varepsilon}$ values easier, than in case of thickness of cut using. At the figures quadratic polynomial was used as a regression model, basis on research results [4] in which burrs 
height has minimum in function of cutting parameter $v_{c}$. From other research $[2,3]$ follows, that federate has similar impact on chips burrs and serration, but lesser than $v_{c}$.

From the figure 6 follows that heat resistant alloys: Waspaloy and Inconel 718 are characterized by the highest burrs occurring independently of federate $f$ and corner radius $r_{\varepsilon}$. The $f / r_{\varepsilon}$ ratio has considerable impact on burrs height $h$ for three of investigated materials: stainless steel, titanium alloy and Inconel X750. For the materials with increasing ofthe $f / r_{\varepsilon}$ ratio both pitch $b$ and height $h$ of the burrs firstly decrease and then can slightly increase when the serration begin to appears. Below ratio $f / r_{\varepsilon}$ corresponding to the smallest burrs height $h$ the burrs arising is connected with smaller thickness of cut than minimal and under the ratio the burrs arising is connected with chips surface serration. After beginning of serration the continuous increase of the $f / r_{\varepsilon}$, causes that burrs connected with the serration becomes much more severe.

Comparing figures 6 and 7 is also visible that the highest burrs height $h$ is connected with occurrence the highest burrs distance $b$.

\section{Conclusions}

The large burrs are usually arised for smaller federates $f$ and higher corner radiuses $r_{\varepsilon}$, due to instability of chips formation in regions of the chips where thickness of cut is smaller than minimal. Whereas small burrs occureence are usually connected with the chips serration when the burrs distance is equal to serration distance $a=b$.

Waspaloy and Inconel 718 are characterized by the highest burrs, occurring independently of the $f$ and $r_{\varepsilon}$ values. For other investigated materials with increasing ofthe $f / r_{\varepsilon}$ ratio (proportional to thickness of cut) both pitch $b$ and height $h$ of the burrs firstly decrease and then can slightly increase when the serration begin to appears. The serration is visibled for stainless steel and titanium alloy only, what is connected with higher cutting speed $v_{c}$ applied for the materials than for heat resistant alloys, the most probably.Minimal values of the $h$ and $b$ dimensions is occured for ratio $f / r_{\varepsilon}=0,15-0,25$ depending on work material. It corresponds to: $f=0,06-0,1 \mathrm{~mm} / \mathrm{rev}$ for $r_{\varepsilon}=0,4 \mathrm{~mm}, f=0,12-0,2 \mathrm{~mm} / \mathrm{rev}$ for $r_{\varepsilon}=0,8 \mathrm{~mm}$ and $f=0,18-0,3 \mathrm{~mm} / \mathrm{rev}$ for $r_{\varepsilon}=1,2 \mathrm{~mm}$. It is optimal range of feedrate from the point of view of machined surface roughness the most probably, what need to be verified.

Acknowledgments: The paper is supported by The National Centre for Research and Development (Project No. PBS3/B5/36/2015).

\section{References}

1. C. Veiga, J.P. Davim, A.J.R. Loureiro, Rev. Adv. Mater. Sci. 34 (2013)

2. A. Daymi, M. Boujelbene, S. Ben Salem, B. Hadj Sassi, S. Torbaty, Archives of Computational Mat. Science and Surface Eng.,1, 2 (2009)

3. T. Mabrouki, L. Deshayes, J. -F. Rigal, K. Jurrens, R. Ivester, Proceedings: 7th CIRP Intl Workshop on Modeling of Machining Operations, (2004)

4. F. Ning, F.Wang, Z. Jia, J. Ma, Int. J. Machining and Machinability of Materials 15, $3 / 4$ (2014)

5. D. Przestacki, Procedia CIRP 14, 229-233 (2014)

6. P.Szablewski, E. Weiss, T. Chwalczuk, Mechanik 89, 8-9 (2016)

7. D. Przestacki, M. Jankowiak, Journal of Physics: Conference Series 483, 012019, 1-7 (2014) 